\title{
Childhood Immunization Refusal: The Return of Vaccine-Preventable Diseases
}

\section{Eunha Shimi*}

Department of Epidemiology, Graduate School of Public Health, University of Pittsburgh, Pittsburgh, PA 15261, USA

Vaccines are considered the most effective prevention tools against infectious diseases, and routine vaccination in the U.S. has led to successful suppression of many such diseases. In fact, vaccinepreventable diseases such as smallpox, polio, diphtheria, mumps and rubella occur at rates that are less than $1 \%$ of what they were during the pre-vaccine era [1]. In fact, immunization requirements for school entry in the U.S. date back to 1855 [1], and they have effectively protected students from many vaccine-preventable diseases. Therefore, high vaccine coverage levels have resulted in herd immunity throughout the population, thus greatly reducing or eliminating continual endemic transmission of a number of diseases.

Due to such drastic reductions in the incidence of vaccinepreventable diseases, however, the memory of several of these dangerous, infectious diseases has faded from public consciousness. A lack of personal experience with diseases like measles and pertussis has led certain parents to focus on vaccine-adverse events and to refuse vaccination [2]. Studies have linked increases in vaccine refusal to parents' concerns about the safety, efficacy and side effects of the vaccines, and to a perception that children's immune systems could not handle the number of vaccines administered simultaneously [3-6]. Specifically, $26 \%$ of parents preferring alternative schedules (compared to the schedule recommended by the Advisory Committee on Immunization Practices) for vaccinating their children were reported to have refused the MMR vaccine for their child, while a further $54 \%$ delayed this vaccine [5].

Such vaccine refusals have resulted in a decrease in vaccine coverage, which has led to a number of outbreaks of measles and pertussis in the U.S. According to the 2009 National Immunization Survey, $25.8 \%$ of parents with children aged $24-48$ months delayed one or more recommended vaccine doses for their children, $8.2 \%$ refused one or more recommended vaccine doses, and 5.8\% both delayed and refused vaccines [5]. Vaccine coverage among the children of parents who delayed and refused was found to be significantly lower for nine of the ten recommended childhood vaccines including diphtheriatetanus-acellular pertussis $(65.3 \%$ vs. $85.2 \%)$ and measles-mumpsrubella $(68.4 \%$ vs. $92.5 \%)$ [5].

In 2000, the measles virus was eliminated from the U.S. as a result of successful implementation of measles vaccination programs. However, since then, vaccine refusal combined with importations of measles into the U.S. has resulted in measles outbreaks. In 2011, 17 measles outbreaks were reported to the CDC (Centers for Disease Control and Prevention) and a total of 222 people in the U.S. contracted measles, the most documented cases in a single year since $1996[7,8]$. Of the 222 cases, $112(50 \%)$ were associated with the 17 domestic outbreaks, and 200 (90\%) were associated with importations from other countries. Most of the patients (86\%) were unvaccinated or had unknown vaccination status. Of the 17 measles outbreaks in 2011, the Minnesota outbreak was the largest outbreak in the US since 1991 [7,9]. The outbreak originated when a 30-month-old toddler returned from a trip to Kenya. The toddler directly infected three others at a day-care facility, and subsequently additional individuals were exposed, including seven infants who were too young to receive MMR vaccine [7,9]. Many infected children during this outbreak in Minnesota were unvaccinated due to parental concerns about MMR vaccine safety [7].

Another large measles outbreak occurred in San Diego, California in 2008. This outbreak began when an intentionally unvaccinated 7-year-old boy who was unknowingly infected with measles returned from Switzerland. The importation resulted in the largest outbreak in San Diego since 1991, exposing 839 persons and infecting 11 (all unvaccinated children) [10]. In the 2008 outbreak of measles in San Diego, California, half of the cases occurred among children whose parents refused vaccination for their children on philosophical or religious grounds [5]. Many parents of this population believed that vaccinations could cause autism in their children [11]. Furthermore, it was found that the San Diego outbreak was attributable to clusters of intentionally unvaccinated children [10]. Recently, there have been numerous other measles outbreaks, such as in Tucson, AZ [11]; Los Angeles County, CA [12]; and in Western and Central Pennsylvania $[13,14]$.

In addition to the suffering caused to these children, treatment and prevention of these outbreaks can carry unfavorable economic costs: up to $\$ 25,000$ in the case of a single infected foreign refugee in the US [15]. During the Tucson outbreak, two hospitals spent approximately $\$ 800,000$ treating seven patients [11]. Remarkably, it costs only $\$ 78$ to vaccinate an individual for measles [16].

Similarly to the US, Canada eliminated endemic measles transmission at the close of the 90s. Five years ago, however, Canada endured its first outbreak since 2000. The outbreak manifested through several unrelated networks of unvaccinated people, lasted 25 weeks, and resulted in 94 cases of measles [17]. Overseas countries such as the United Kingdom have been striving to eliminate endemic measles transmission but are held back by low vaccination uptake in children. In Merseyside, UK, a vaccination uptake of only $85 \%$ for the second dose in children younger than five has led to the largest outbreak in the northwestern UK since 1996 [18]. The outbreak began in January 2012 and as of June 30th 359 confirmed and 157 probable cases of measles were reported [18]. Only $3 \%$ of the vaccine-eligible confirmed cases were fully immunized. As a result of this outbreak, existing vaccination initiatives in the area have been intensified [18].

Pertussis is another vaccine-preventable disease whose spread in the

*Corresponding author: Eunha Shimi, Department of Epidemiology, Graduate School of Public Health, University of Pittsburgh, Pittsburgh, PA 15261, USA, Tel: (412) 383-8085; Fax: (412) 624-7397; E-mail:eshim@pitt.edu

Received Novemer 30, 2012; Accepted December 05, 2012; Published December 07, 2012

Citation: Shimi E (2012) Childhood Immunization Refusal: The Return of Vaccine-Preventable Diseases. J Vaccines Vaccin 3:e115. doi:10.4172/2157$7560.1000 \mathrm{e} 115$

Copyright: (c) 2012 Shimi E. This is an open-access article distributed under the terms of the Creative Commons Attribution License, which permits unrestricted use, distribution, and reproduction in any medium, provided the original author and source are credited. 
Citation: Shimi E (2012) Childhood Immunization Refusal: The Return of Vaccine-Preventable Diseases. J Vaccines Vaccin 3:e115. doi:10.4172/21577560.1000 e115

U.S. is enabled by vaccine refusal. More than 32,000 cases of pertussis were reported in 2012, the largest occurrence in 12 years [19]. Recent outbreaks and high rates of pertussis were reported in Washington, Colorado, Minnesota, and Wisconsin [19]. Risk factors for contracting pertussis include incomplete vaccinations and waning immunity [2022]. Unlike measles, immunity from the pertussis vaccine begins to wane 5 to 10 years after completion of the childhood immunization schedule, thus leaving adults and adolescents at high risk [21]. Still, unvaccinated children are eight times more likely to contract pertussis than vaccinated ones [23]. Similarly to measles, clusters of intentionally unvaccinated children exist in the U.S. Previous studies have indicated that the risk of community-level pertussis outbreaks is greatly increased by the presence of these geographically concentrated exemptors [24,25]. Another study found higher risk of pertussis associated with exposure to exemptors in school outbreaks, as well as higher incidence of pertussis among vaccinated children living in counties with exemptors [25].

In order to understand the impact of vaccine exemptions on the potential resurgence of once-eradicated infectious diseases, mathematical models of vaccination behavior have been developed [2,26-29]. These studies show that vaccine refusal not only increases the individual's risk of disease but also increases the risk for those who cannot be vaccinated due to medical conditions, those too young to be vaccinated, and those who were vaccinated but did not mount an immune response due to vaccine failure. Major reasons for vaccine refusal in the U.S. are parental concerns about the safety of vaccination as well as a lower level of concern about the risk of infection. Therefore, if the vaccination levels necessary to achieve the population's herd immunity are to be maintained, increased efforts will be needed to educate the public on vaccine safety and infection risks.

\section{References}

1. Jacobson RM (2012) Vaccinations: a public health triumph and a public relations tragedy. Minn Med 95: 36-40.

2. Shim E, Grefenstette JJ, Albert SM, Cakouros BE, Burke DS (2012) A game dynamic model for vaccine skeptics and vaccine believers: measles as an example. J Theor Biol 295: 194-203.

3. Salmon DA, Moulton LH, Omer SB, DeHart MP, Stokley S, et al. (2005) Factors associated with refusal of childhood vaccines among parents of school-aged children: a case-control study. Arch Pediatr Adolesc Med 159: 470-476.

4. Smailbegovic MS, Laing GJ, Bedford $H$ (2003) Why do parents decide against immunization? The effect of health beliefs and health professionals. Child Care Health Dev 29: 303-311.

5. Smith PJ, Humiston SG, Marcuse EK, Zhao Z, Dorell CG et al. (2011) Parenta delay or refusal of vaccine doses, childhood vaccination coverage at 24 months of age, and the Health Belief Model. Public Health Rep 126: 135-146.

6. Gust DA, Darling N, Kennedy A, Schwartz B (2008) Parents with doubts about vaccines: which vaccines and reasons why. Pediatrics 122: 718-725.

7. Centers for Disease Control and Prevention (2011) Measles: United States, January--May 20, 2011. MMWR Morb Mortal Wkly Rep 60: 666-668.

8. Centers for Disease Control and Prevention (2012) Measles Outbreaks.

9. Centers for Disease Control and Prevention (2011) Notes from the field Measles outbreak--Hennepin County, Minnesota, February-March 2011. MMWR Morb Mortal Wkly Rep 60: 421.

10. Sugerman DE, Barskey AE, Delea MG, Ortega-Sanchez IR, Bi D, et al. (2010) Measles outbreak in a highly vaccinated population, San Diego, 2008: role of the intentionally undervaccinated. Pediatrics 125: 747-755.

11. Chen SY, Anderson S, Kutty PK, Lugo F, McDonald M, et al. (2011) Health care-associated measles outbreak in the United States after an importation: challenges and economic impact. J Infect Dis 203: 1517-1525.

12. Centers for Disease Control and Prevention (2012) Measles outbreak associated with an arriving refugee - Los Angeles County, California, AugustSeptember 2011. MMWR Morb Mortal Wkly Rep 61: 385-389.
13. Centers for Disease Control and Prevention (2012) Hospitalassociated measles outbreak - Pennsylvania, March-April 2009. MMWR Morb Mortal Wkly Rep 61: 30-32.

14. Centers for Disease Control and Prevention (2008) Multistate measles outbreak associated with an international youth sporting eventPennsylvania, Michigan, and Texas, August-September 2007. MMWR Morb Mortal Wkly Rep 57: 169-173.

15. Coleman MS, Garbat-Welch L, Burke H, Weinberg M, Humbaugh K, et al. (2012) Direct costs of a single case of refugee-imported measles in Kentucky. Vaccine 30: 317-321.

16. Zhou F, Reef S, Massoudi M, Papania MJ, Yusuf HR, et al. (2004) An economic analysis of the current universal 2-dose measles-mumps-rubella vaccination program in the United States. J Infect Dis 189: S131-S145.

17. Dallaire F, De Serres G, Tremblay FW, Markowski F, Tipples G (2009) Long-lasting measles outbreak affecting several unrelated networks of unvaccinated persons. J Infect Dis 200: 1602-1605.

18. Vivancos R, Keenan A, Farmer S, Atkinson J, Coffey E, et al. (2012) An ongoing large outbreak of measles in Merseyside, England, January to June 2012. Euro Surveill 17.

19. Centers for Disease Control and Prevention (2012) Pertussis Outbreaks.

20. Berger F, Njamkepo E, Minaberry S, Mayet A, Haus-Cheymol R, et al. (2010) Investigation on a pertussis outbreak in a military school: risk factors and approach to vaccine efficacy. Vaccine 28: 5147-5152.

21. Khan FN, Lin M, Hinkle CJ, Franklin P, Luther R, et al. (2006) Casecontrol study of vaccination history in relation to pertussis risk during an outbreak among school students. Pediatr Infect Dis J 25: 1132-1136

22. Schafer S, Gillette H, Hedberg K, Cieslak P (2006) A community-wide pertussis outbreak: an argument for universal booster vaccination. Arch Intern Med 166: 1317-1321.

23. Centers for Disease Control and Prevention (2012) Pertussis epidemic--Washington, 2012. MMWR Morb Mortal Wkly Rep 61: 517-522.

24. Omer SB, Enger KS, Moulton LH, Halsey NA, Stokley S, et al. (2008) Geographic clustering of nonmedical exemptions to schoo immunization requirements and associations with geographic clustering of pertussis. Am J Epidemiol 168: 1389-1396

25. Feikin DR, Lezotte DC, Hamman RF, Salmon DA, Chen RT, et al (2000) Individual and community risks of measles and pertussis associated with personal exemptions to immunization. JAMA 284: 3145-3150.

26. Bauch CT, Bhattacharyya S, Ball RF (2010) Rapid emergence of freeriding behavior in new pediatric immunization programs. PLoS One 5: e12594.

27. Bhattacharyya S, Bauch CT (2010) A game dynamic model for delayer strategies in vaccinating behaviour for pediatric infectious diseases. $J$ Theor Biol 267: 276-282.

28. Shim E, Grefenstette J, Albert S, Cakouros B, Bohn L, et al. (2012) Impact of vaccine behavior on the resurgence of measles, in Modeling the Interplay between Human Behavior and Spread of Infectious Diseases. Springer.

29. Manfredi P, Posta PD, d'Onofrio A, Salinelli E, Centrone F, et al. (2009) Optimal vaccination choice, vaccination games, and rational exemption: an appraisal. Vaccine 28: 98-109. 